\section{J.R. Moehr}

School of Health Information Science University of Victoria

Victoria, BC,Canada

\section{History of Medical Informatics}

Place: Reisensburg Castle (near Ulm, Germany)

Participants: See Participant List

Time: May 2 - 4, 1973

I: May 2, 1973

Morning Session

Start 9:30, End 12:30

Dr. Reichertz welcomes the participants and explains the goal and purpose of the meeting. From the ensuing discussion, the following agenda for the meeting results:

1 Definition of the tasks of a "Medical Informatician"

1.1Contents 1.2Distinction from Other

Areas of Competence

2 Professional Roles 2.1Professional Role Matrix 2.2Contents

3 Ideal Curricula

4 Realization 4.1General Solutions 4.2Transitional Solutions

5 Strategies for Realization

6 Final Paper for Documentation of Results.
The plan is to cover agenda items 1 -2 by the evening of May $2^{\text {nd }}$, item 3 should be worked out in separate working groups of medical and computer science participants, and the results are then to be harmonized in a plenary discussion. There was agreement that many agenda items are mutually related and that overlaps in the discussion are to be expected.

Regarding the intended final document, it has to be left open whether this will take the form of minutes which have to be discussed further by the (sponsoring) societies ${ }^{2}$, or whether it will take the form of a final recommendation. Further discussions should begin immediately after dinner on the $2^{\text {nd }}$ of May, and should be continued throughout the other evening sessions. Agenda items 5 and 6 are to be discussed on May $4^{1}$. The end of the workshop is set for Friday, $12: 30 \mathrm{pm}$.

\section{Agenda item 1.1 \\ Definition of the Tasks of the Medical Informatician}

The distinction of Informatics (Computer Science) and Information Science are discussed. (Prof. Diemer in Düsseldorf and Dr. Wersig, Berlin, are cited as examples of information scientists). It is stated that both are different, albeit overlapping areas; for the purpose of subsequent discussion, informatics will be taken to be the field addressed by the $2^{\text {nd }}$ Data Processing Program (and the interregional research program "Informatics") and as represented by the curricula of informatics at German institutions of advanced scientific education. The importance of team work in medical informatics is repeatedly emphasized.

The tasks of medical informatics are envisioned as the documentation, analysis, direction, regulation and synthesis of information processes in health care, or rather in the entire health system. "Medical Informatics" is therefore seen as part of an endeavour

\footnotetext{
1 Due to an error in the original minutes, the $5^{\text {th }}$ of May is given as the date here.

2 The sponsoring societies were the Society for Medical Documentation and Statistics (Gesellschaft für Medizinische Dokumentation und Statistik e.V., GMDS) and the Society for Informatics (Gesellschaft für Informatik e. V., GI)
} 
to optimize patient care and therefore has to be subservient to patient care.

The discussion around the definition of the patient care system and the health care system resulted in identifying the following fields of activity of future Medical Informaticians:

1 Inpatient care (hospitals, including rehabilitation)

2 Outpatient care (physicians' practices)

3 Public health services, including prevention

4 Environmental protection

5 Medical research in all its facets

6 Education in health care (basic, additional and continuing education $^{3}$ of all health related professionals, and also patient education)

7 Medical informatics proper

Within these seven application areas, five functional areas are distinguishable:

a. Medical technology including measurement technology (Laboratory, nuclear medicine, ECG, intensive care, etc.)

b. Clinical medicine (patient history, clinical examination, therapy, etc.)

c. The administrative area including organizational tools, and organizational management

d. ' $x$ ', for which an unambiguous label could not be determined. It encompasses analysis and assessment of information, modeling, simulation, development of methods, provision of decision support, development of reporting and alarm systems, etc.

e. Education and training.

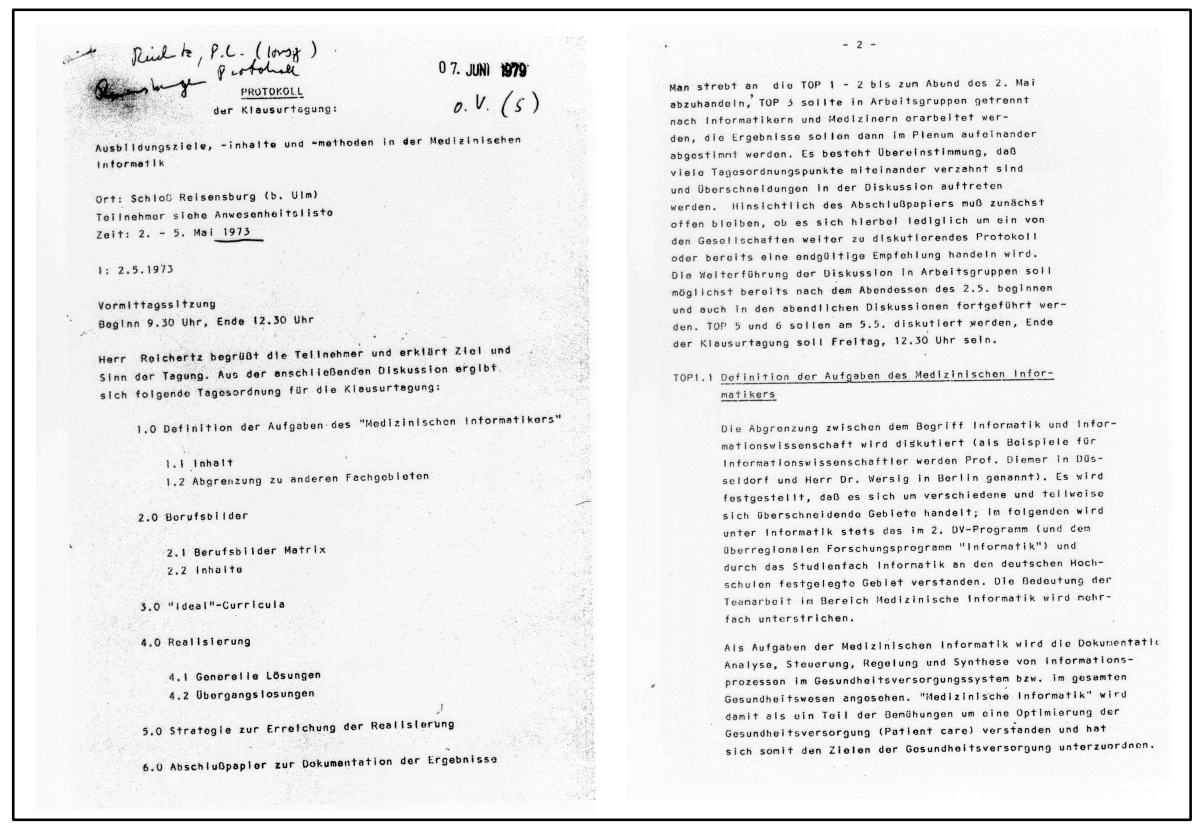

Page 1 and 2 of the Reisensburg-Protokoll*

The above leads to a 7 by 5 matrix. The discussion revealed that it is presently unclear whether all cells of this matrix make sense and are unambiguous. The matrix probably has to be modified but could meanwhile serve as a basis for the discussions.

\section{Afternoon session 2:30 to $6: 30 \mathrm{pm}$}

The discussion of agenda item 1 (Tasks of Medical Informatics) was continued with respect to its informatics component.

Given the stated goals of:

1. Data capture;

2. Information assessment;

3. Information storage and management;

4. Information evaluation; and

5. Process control, the following areas of activity were discussed:

a. Signal - and data generation
I. Data identification

II. Data capture

III.Storage and management of data collections

b. Action (comparator, control mechanism)

c. Transmission and preparation (validation, correction) of data

d. Manipulation (processing, storage, retrieval and display) of data

e. System regulation, process control, simulation.

Responsibly performing these activities requires methodological and technical knowledge.

\section{Re: a) Acquisition:}

Sensors, quantization (including A/ $\mathrm{D}$ and D/A conversion, specific medical problems associated with data and signal acquisition (such as psychological issues associated with interview and questionnaire

\footnotetext{
3 The German system of medical education consists of basic medical education, which leads up to a state examination at the level of an M.D. in the North American system. A doctoral degree is not conveyed at this point but contingent upon an optional completion of a dissertation. Attainment of the equivalent of a board certified specialty designation, e.g., for internal medicine, is contingent on additional education and completion of an operational qualification of several years' duration. In addition, every medical practitioner is obliged to complete continuing education.

* A PDF file of the complete German version of the text can be requested at: jmoehr@uvic.ca or at reinhold.haux@umit.at
} 
techniques, etc.), construction and use of vocabularies (thesauri), coding and classification, ergonomics (operator console, process control panels), validation, instrumentation, external data sources.

\section{Re: b) Data transmission}

Manual and automated approaches, components, transmission methods, circuits, data protection and data security.

\section{Re: c) Information processing} Functional components and operation of analog and digital computers, storage hierarchies (and access characteristics), functional components and use of operating systems, data structures, documentation and information systems, including data bases, programming languages, program construction (design and implementation), programming principles (such as sorting algorithms), real time operation (time critical problems), presentations.

\section{Re: d) Modeling}

Simulation, pattern analysis, decision theory and decision models, process control, approaches to systems analysis.

\section{Agenda Item 1.2 \\ Distinction from other areas of competence}

For lack of time, this topic was only briefly discussed. Some argued that there is no separate field of "Medical Informatics", and that only areas of activity had been described. This was countered with structured considerations of workin hospitals and definitions of chairs at universities. A more thorough discussion of this issue is necessary.

\section{Evening Session \\ Agenda Item 2: Professional Roles}

The discussion was introduced by alerting to the potential development of social conflict, e.g., if a physician specialist in informatics (certified by an appropriate medical board) and an informatician, who does not have access to the same certification are fulfilling the same functions, potentially under the same roof. The medical participants suggested that it would be desirable to work towards a solution which is applicable to informaticians as well as physicians in analogy to the solution found for physicians and chemists by the Society for Clinical Chemistry (i.e., remuneration of a chemist like a medical chief of service, including fee for service reimbursement, etc.). In support of this point, reference is made to: I. Stamm, H. Breuer: Profession of the Clinical Chemist and Clinical Biochemist, published by the German Society for Clinical Chemistry, under then Secretary, current President: Prof. Dr. Dr. H. Buettner, Institute of Clinical Chemistry, Hannover Medical School, 3 Hannover-Kleefeld. ${ }^{4}$

The purpose of the approach of the Society for Clinical Chemistry is to identify the prospective areas of activity for clinical chemists, and to provide a unified professional reality despite diverging initial prerequisites. The informaticians counter that this approach would result in importing social tensions from the realm of medicine into that of informatics and that therefore it would be preferable to change the structures and behaviours in the medical system as the real cause of the problem. The medical participants emphasize the reality of the comprehensive health care system. These realities have to be taken into consideration if one strives to create adequate professional positions for informaticians.

Available alternatives were discussed for medical as well as informatics professionals:

- University education

- Post graduate education

- Medical specialization

- Doctoral education.

Therefore, issues of basic education were discussed as well as issues of additional and continuing education.

In order to approach a solution, a catalogue of medical subjects was sketched that would be suitable for candidates with an education in informatics (with a minor in medicine or a minor in another subject, or with additional education in medicine, including continuing education).

1. Structure and function of the human body (e.g., organ functions such as respiratory, circulatory and digestive system, and the interaction of such systems). In contrast to the offerings in anatomy and physiology for medical students, these offerings are, however, not intended to convey detailed knowledge, but to impart a general conceptual understanding.

2. Introduction to nosology (with components of pathology and pathophysiology).

3. Therapeutic principles. This would include manual, assistive device-based, drug-related, surgical and general measures.

4. Medical terminology.

5. A methods critique of medical thought and decision processes. This should include the development of a general medical

4 A copy of this publication was provided as attachment to these minutes. 
methodology, and a presentation of the approaches to empirical information gathering, and the subsequent decision process underlying medical action. This should include the interaction of different medical specialties and their mutual distinction.

6. Clinical chemistry and clinical physiology and their approaches. This should include laboratorybased approaches and the associated instrumentation (e.g., radiologic and nuclear medicine approaches)

7. Human ecology. This should include problems of ecology, sociology and psychology.

8. Hospital management.

9. Health care system organization.

10.Different application areas:

- Modeling in biology and medicine

- Biostatistics

- Biosignal processing

- Documentation and reporting of medical findings.

Basic education should emphasize biomathematical models, such as those used in epidemiology, and it should cover methods of biosignal processing, such as have been employed for surveillance of critically ill patients (patient monitoring).

The inclusion of practical education should be pursued. The categories $1-$ 3 above are core subjects and could form the components of basic studies. Curricular offerings for medical technicians, medical record administrators or biomedical engineers might serve as appropriate models.

It was emphasized that the goal should not be to produce a medical person with inferior qualifications. It was felt to be essential to strive for integrative representations which transcend the conventional medical subjects and lead the informatician towards a deeper understanding of medicine, in order to prepare him for specific professional activities.

\section{May 3, 1973 Morning Session}

Pursuant to the preceding evening session, the completeness of the catalogue of medical subjects for informaticians was checked. It was decided to refrain for now from a more detailed description. A further detailing of the "methods critique of medical thought and decision processes" is required. The discipline of medical documentation technicians is to be included in the considerations.

\section{Agenda Item 2 \\ Professional roles}

At the level of graduates of academic programs, the following structure was developed, with considerable emphasis on symmetry (the abbreviations used should be taken as preliminary working titles):

1. Education in informatics for physicians ("M")

\subsection{Student}

1.1.1. All medical students (introductory lectures, general introductions, summary of new approaches)

1.1.2. Medical students with minor in informatics. Currently the medical curriculum does not offer the option of a minor in another field. Itmight have to be additional education. A fundamental course for conveyance of basic concepts [in informatics] should be incorporated into the general curriculum.

1.2. Supplemental Education (physician, supplemental qualification in informatics: "M"

1.2.1. Diploma or "PhD"; it is envisioned that a physician with earned doctorate in medicine might earn a doctoral degree in a medical faculty, e.g., a Dr.phil.med., Dr. rer.biol.human. or similar degree, or, in exceptional cases, through a dissertation in informatics at an informatics faculty.

1.2.2. Medical Specialty Board Examination.This was envisioned in analogy to the clinical chemist and includes "on the job training" (sic.) of 2-3 years with preceding or concurrent theoretical education in informatics. The total required additional education might be 5 years.

2. Education in Medicine for Informaticians (I)

2.1. Students

2.1.1. General students of informatics. At this level, it is not required to provide an introduction to medicine. But it would be desirable that educational counseling includes pointers to the possibilities of a minor in medicine supported by appropriate information.

2.1.2. Student of informatics with application subject medicine. (see above)

2.2. Supplemental Education. (Informatician, additional qualificationin Medicine " $\mathrm{I}_{\mathrm{M}}$ ".

2.2.1. A student of this type had selected a different application subject during his studies of informatics and has to acquire the knowledge that is conveyed in 2.1.2 (catch up on application subject medicine, preparation for a doctoral degree in a medical application area or in specific (medical) application areas).

2.2.2. Operational Qualifica- 
tion. On the job training with the goal of attaining competencies equivalent to 1.2.2. There is agreement with respect to the goals of an operational qualification. The informaticians emphasize that it would be a responsibility of medical institutions (e.g., hospitals), to provide continuing education and opportunities for professional advancement to practicing informaticians.

It is stated that related planning would have to address three different levels:

I. Technician(e.g., medicaldocumentation technician, information technician)

II. College degree education

III. University degree education

The option for transition among these levels is considered a requirement, but detailed discussion is deferred to the discussion of educational goals. There is agreement that advancement is contingent on qualifications, which have to be defined diligently. This should include the recognition of certain complexes, which are not to be reiterated in the context of higherlevel education. The question of entrylevel qualifications (e.g., aptitude tests, results of professional activity, etc.) are briefly addressed. Further considerations are deemed necessary, but postponed for lack of time.

Prof. Dudeck presented the profession and curriculum for "Medical Documentation Assistants". The curri- culum contains five areas of instruction:

- Medicine

- Mathematics and statistics

- Documentation

- Data processing

- Hospital organization

There is agreement in principle that this curriculum is independent.

A graduate in informatics with application subject medicine is proposed at the level of vocational colleges 5 in analogy to the academic level of education at universities. An analogous situation does not exist on the medical side (Note: At the level of the Science Council ${ }^{6}$, the education of medical specialists with diploma ${ }^{7}$ has been recommended of late for advanced nurses, hospital operational engineers, and laboratory engineers. This would come close to the level considered here.)

Guidelines and recommendations of the working group should be worked out for a minor in medicine for informaticians at vocational colleges. There is agreement that the medical subjects should amount to around 20 $30 \%$ of the entire curriculum. A $50 \% /$ $50 \%$ division among medicine and informatics is rejected.

The problem of the vocational college in Heilbronn ${ }^{8}$ and its approach are briefly discussed. The goal of educating college level informaticians with application subject medicine is acknowledged as desirable in principle. However, in the opinion of the discussants, the curriculum revealed to date (May 1973) does not warrant the granting of a title "Diploma of
Medical Informatics"9, 10 - neither from the perspective of informatics nor that of medicine. It is stated that the curriculum revealed so far is more at the level of documentation assistants ${ }^{11}$.

Overall, the following tiers result:

I. Medical Documentation Assistant $^{11}$

II. Informatician with vocational college education with application subject medicine

III. $\mathrm{M}_{\mathrm{I}}$ and $\mathrm{I}_{\mathrm{M}}$

The working group acknowledges that other entry levels for professional activity in medical informatics are conceivable. The practical experience shows that economists, mathematicians and physicists have become experts in the field. Transitional and educational solutions for such personnel have to be discussed. It is considered appropriate, in principle, to first define the professional orientation and educational plans for medical personnel and informaticians, in order to then be able to address other professional orientations through exchange of individual modules.

\section{Afternoon}

The discussion addressed:

\section{Agenda Item 3: Ideal Curricula} Agenda Item 4: Realization

Inparticular, initially:

Application subject medicine

- Additiontal education medicine

- Operationalqualification

For graduates of university education in informatics ${ }^{12}$.

\footnotetext{
${ }^{5}$ Fachhochschulen

${ }^{6}$ Wissenschaftsrat

${ }^{7}$ Diplom Mediziner

8 "Fachhochschule Heilbronn" also sometimes translated as "University of Applied Sciences, Heilbronn"

${ }^{9}$ Diplom Informatiker der Medizin

${ }^{10}$ Male gender used here

${ }^{11}$ Female gender used here

${ }^{12}$ Diplom Informatiker
} 
1. Application subject medicine for students of informatics at universities.

The discussion of the minor in medicine started with an optimal wish list. Subsequently, this was adapted to a total of 40 hours per week ${ }^{13}$ spread over the curriculum until graduation. Studies in informatics currently include education in one [of several alternative] application subjects with an allocation of $25 \%$ of the entire curriculum.

The following catalogue was developed from an "ideal curriculum" for the application subject medicine (educational hours are specified in \% in order to facilitate adaption to local conditions). There is also an indication whether it is recommended to cover the subjectduring basic education ${ }^{14}$ or later ${ }^{15}$

Fifty-one percent of this catalogue are assigned to the studies towards the "Vordiplom" and 49 to the studies towards the final examination. Shifts among these allocations are possible. The courses covering "Structure and Function of the Human Body" and "Medical Terminology" should be offered at the beginning of the application subject.
The following subjects are recommended as electives for further in depth studies:

- Statistics

- Operations Research

- Microeconomics/Business Administration

The discussion of a hospital practicum, offered as block course of two weeks' duration, raised pros and cons. It was considered desirable to introduce students to hospital operation, e.g., in the context of work on a diploma thesis. A practicum in analogy to an industrial internship was not recommended. The option of conducting seminars in hospitals was also discussed.

2. Additional Studies in Medicine for Informaticians with university education $^{12}$

Two cases can be distinguished:

(I) Diplom Informatician, Application Subject Medicine

(II) Diplom Informatician, Other Application Subject

It can be assumed that the emphasis of professional activity is well defined for students engaging in additional studies. In case (I), one can also assume that enough basic knowledge in medicine is available to decide independently on a course of professional specialization. The catalogue of minor subjects can serve as orientation for individuals who fall into category II. It is conceivable that curricula will be defined/offered in this area in the context of the federal initiative for the advancement of graduates $^{16}$.

\section{Operational Qualification}

The discussion of operational qualification used the recommendations for clinical chemists as a model. The goal currently pursued by those working in medical informatics, is to open up career opportunities in health care, which allow to reach a status that is equivalent to a chief of service in hospitals.

There is agreement that numerous professional roles are available to the medical informaticians, the most important of which are:

- Director of computing centre in medium or large hospitals

- Director of a division of medical data processing in hospitals (both positions with management

\begin{tabular}{|l|c|c|}
\hline & $\begin{array}{c}\text { Weight } \\
\%\end{array}$ & $\begin{array}{c}\text { V Vordiplom } \\
\text { D Diplom }\end{array}$ \\
\hline Structure and Function of the Human Body & 20 & V \\
\hline Nosology (Pathophysiology) & 14 & V \\
\hline Therapeutic Principles & 6 & $\mathrm{D}$ \\
\hline Medical Terminology & 3 & $\mathrm{~V}$ \\
\hline Methods Critique of Medical Thought and Decision Processes & $5 ?$ & $\mathrm{D}$ \\
\hline Clinical Chemical and Clinical Physical Methods & $8 ?$ & $\mathrm{~V}$ \\
\hline Man and Environment & 4 & $\mathrm{D}$ \\
\hline Hospital Operations and Management & 6 & $\mathrm{D}$ \\
\hline Organizational Structures in Health Care, Legal Issues & 6 & $\mathrm{~V}$ \\
\hline Biostatistics & 6 & $\mathrm{D}$ \\
\hline Biomathematical Models (including Epidemiology) & 4 & $\mathrm{D}$ \\
\hline Special Problems of Medical Data Processing, Medical ...(illegible) & 14 & $\mathrm{D}$ \\
\hline Documentation & 4 & $\mathrm{D}$ \\
\hline
\end{tabular}

\footnotetext{
${ }^{13}$ In the German system of advanced education, educational exposure is measured in hours per week per semester. Three hours per week per semester correspond roughly to one course in the North American system.

14 i.e., before the "Vordiplom", equivalent to a bachelor's degree, which is not a professionally qualifying exam in Germany.

15 i.e., between "Vordiplom" and "Diplomprüfung", before the final examination which is equivalent to a Masters degree in North America.

${ }^{16}$ Graduierten Förderungsgesetz
} 
functions correspond to those in medical service divisions)

- Director of a division for medical informatics in third party payers/ insurance companies

- Director of a division of medical dataprocessing in other medical institutions, such as

- Public health institutions

- Medical clinics

- Diagnostic centres

- Director of a scientific department of medical (clinical) informatics in research institutions

- Director of a division of medical information systems in industry.

There is agreement that an operational qualification may be required and may be subjected to examination, and to attestation through a certificate. However, it was not possible to achieve agreement with respect to how to operationalize and institutionalize this approach. The informaticians emphasized that the granting of academic titles, which are based on scientific education and pursuit of scientific work are the responsibilities of scientific academic institutions such as universities. It is also cautioned on the part of the informaticians that it is not necessarily desirable to differentiate informaticians in hospitals from those, e.g., in public administration (e.g., with responsibility for finance) because both professional groups have to be equally qualified and are carrying equivalent responsibilities.This argument is countered by the medical attendants by pointing out that continuing education and specialization programs exist in medicine as well as in the legal profession, which have operational qualification as a prerequisite and which are a prerequisite to the performance of certain medical functions (examples include recognition as medical specialists or fulfilling the functions of a judge).

\section{Evening Session}

The subject of discussion was: Additional studies in informatics for graduates of medicine

A minor in informatics in the context of studies of medicine was deemed not realizable at present. Other than in the case of a curriculum of informatics, a minor subject is at present not part of the medical curriculum. Foreign components are firmly integrated [into the medical curriculum]. However, it is considered desirable to make certain fundamentals of medical informatics an integral part of the medical curriculum.

Regarding the additional studies, a medical specialization (in medical informatics) or pursuit of a scientific career in an academic institution are for now considered potential goals. The catalogue below could be considered a core for additional education in informatics for medical graduates(additional education in the word's comprehensive sense. Thenumbersin brackets below indicate lectures and exercises [in hours per week per semester $]^{13}$ ).

The combinations I and II and II and III are considered particularly important among the possible combinations that arise from the table above. Given enough interest, the combination of all three streams should not be excluded either.

\begin{tabular}{|c|c|c|}
\hline \multicolumn{3}{|c|}{$\begin{array}{ll}\text { Introduction to informatics: } & 2 \mathrm{x}(3+2) \\
\text { Functional architecture of computers: } & (2+0) \\
\text { Systems programming (Programming techniques): } & (3+1)\end{array}$} \\
\hline $\begin{array}{l}\text { I } \\
\text { Sub Structures }{ }^{17} \\
(2+0) \\
\text { Information Systems } \\
(3+0)\end{array}$ & $\begin{array}{l}\text { II } \\
\text { Higher programming languages } \\
(2+0) \\
\text { Program construction } \\
(3+0)\end{array}$ & $\begin{array}{l}\text { III } \\
\text { Process control and real time systems } \\
(3+0) \\
\text { Process automation } \\
(2+0) \\
\text { Discrete simulation } \\
(?+?) \\
\text { Graphic data processing } \\
(2+0)\end{array}$ \\
\hline
\end{tabular}

17 "Unterstrukturen", almost illegible in the available copy 
The catalogue above should be complemented by offerings conveying the necessary mathematical prerequisites such as:

- Discrete structures

- Mathematics (e.g., for biologists)

Recommendations for pursuing more in depth studies include:

- Formal languages

- Automata theory

- Pattern recognition

- Operations research

Beyond that the following subjects were identified as desirable:

- Decision Theory

- Business Economics

- Biostatistics

- Documentation

- Methods Critique

- Organizational Studies and Project Management

- Special Subjects of Medical Data Processing

These subjects are not to be provided by informatics but by medical informatics.

It was considered to add the underlined subjects to the core of the additional education.

\section{May 41, 1973}

Morning Session

Agenda Item 4: Realization and Institutionalization of the Educational Plans

As a start, the approaches used by the medical profession were explained in order to recommend adoption or adaptation for institutionalization, since it may be the only way for professionals in medical informatics to attain a secure position within the professional and political structures of medicine.

Many medical specialties convey titles in recognition of specialized competence. The granting of these titles is contingent on meeting requirements of additional education. The medical state examination $^{3}$ is the common prerequisite. In cases where additional qualification would be too time consuming to generate a sufficient number of completely educated graduates, granting of an additional designation is practiced. This additional designation does notimply full qualification and is contingent on an existing title and full qualification in another specialty discipline ${ }^{18}$.

Thesis 88 of the Hartmann Federation ${ }^{19}$ requests inclusion of the "Additional Designation Medical Informatics" in the professional code for the medical profession. In the opinion of the workshop participants, this solution is suboptimal because a thorough education in informatics is required for medical graduates, which would in turn warrant recognition as a medical specialty. It is also emphasized that customarily, the additional designation is only added to an existing specialty title. The fact that a medical specialty title is only available to medical professionals, is in conflict with the desirability of collaboration of graduates of informatics and of medicine.

Further, during a transitional period, a solution for other professionals is also required (economists, engineers, sociologists, physicists, mathematicians). Transitional regulations may also be applied later for members of these professions. The application of the curricular catalogue (see above) and the granting of certificates (see below) to the members of these professional groups is recommended.

The education of informaticians is regulated by an examination framework, which has been adopted by the conference of ministers of culture ${ }^{20}$. This examination framework is linked to recommendations of the Society for Applied Mathematics and Mechanics $\left(\mathrm{GAMM}^{21}\right)$ and the Society for Communications Technology $\left(\mathrm{NTG}^{22}\right)$ for the content of informatics curricula. These recommendations ${ }^{23}$ are the basis for allinformatics curriculain Germany.

The clinical chemistry model was referred to again. Since medical specialty titles and additional designation are only available to medical professionals, a solution analogous to that of the German Society forClinicalChemistry forClinical Chemists could lead to a solution of equalization of the professional groups active in medical informatics.

"The German Society for Clinical Chemistry grants a scientific certificate of recognition as Clinical Chemist to chemists and medical graduates who fulfill a defined catalogue of educational requirements and completion of defined practical activities in the area of Clinical Chemistry."

An analogous certificate of recognition as "Medical Informatician" would offer the opportunity to:

\footnotetext{
${ }^{18}$ A common example would be an internist, i.e., specialist in internal medicine, with an additional qualification in balneology.

${ }^{19}$ Hartmann Bund, Verband der Ärzte Deutschlands, an advocacy group for physicians in Germany.

${ }^{20}$ Kultusminister Konferenz, a forum of coordination among the ministers responsible for education at the level of the individual states of the Federal Republic of Germany.

${ }^{21}$ Gesellschaft für Angewandte Mathematik und Mechanik e.V., GAMM.

${ }^{22}$ Nachrichtentechnische Gesellschaft e.V., NTG.

${ }^{23}$ These recommendations formed the basis for education in Informatics/Computer Science and are usually referred to as the 'GAM/NTG Recommendations'.
} 
a. Have members of a variety of professional groups participate in the professional pursuit

b. Control the professional qualification.

The certificate would have to attest complete qualification and should be granted to graduates of medicine and informatics, and during a transition period or after completion of prerequisites yet to be defined, to members of other professional groups. The recognition of a medical specialty [in medical informatics] should in addition be available to medical professionals. This medical specialization could be based on the same prerequisites as the certificate. There was consensus to pass the recommendations that had been worked out on to the medical professional organizations and to the Society for Informatics. The informaticians at the workshop did, however, register serious reservations with the approach that would result in rewarding operational qualification, which is necessary for all professional advancement, for some informaticians with an official certificate. This was feared to result in differences among informaticians of similar qualification, and this solely because potentially obsolete structures and procedures in the domain of medicine make such an approach appear opportune at the moment.

The participants from the medical domain countered by pointing to the need for a controlled additional education, on the grounds that experience in patient-oriented measures can only be gained through pertinent professional action, which in turn means that differential qualifications may well exist, at least in the realm of medicine.
Operational qualification means attainment of the capability to solve medical problems through [additional and] continuing education, work experience and responsible professional activity, not just scientific qualification in a more narrow sense. Autonomous creative productivity is required in this context, and work according to the principles of scientific analysis and innovation.

The following is a time chart for possible educational alternatives:

The subsequent discussion led to the following program for attainment of operational qualification. The specified minimal times should be fulfilled by every applicant. The remaining time should be devoted to the subjects identified as core " $\mathrm{C}$ ":

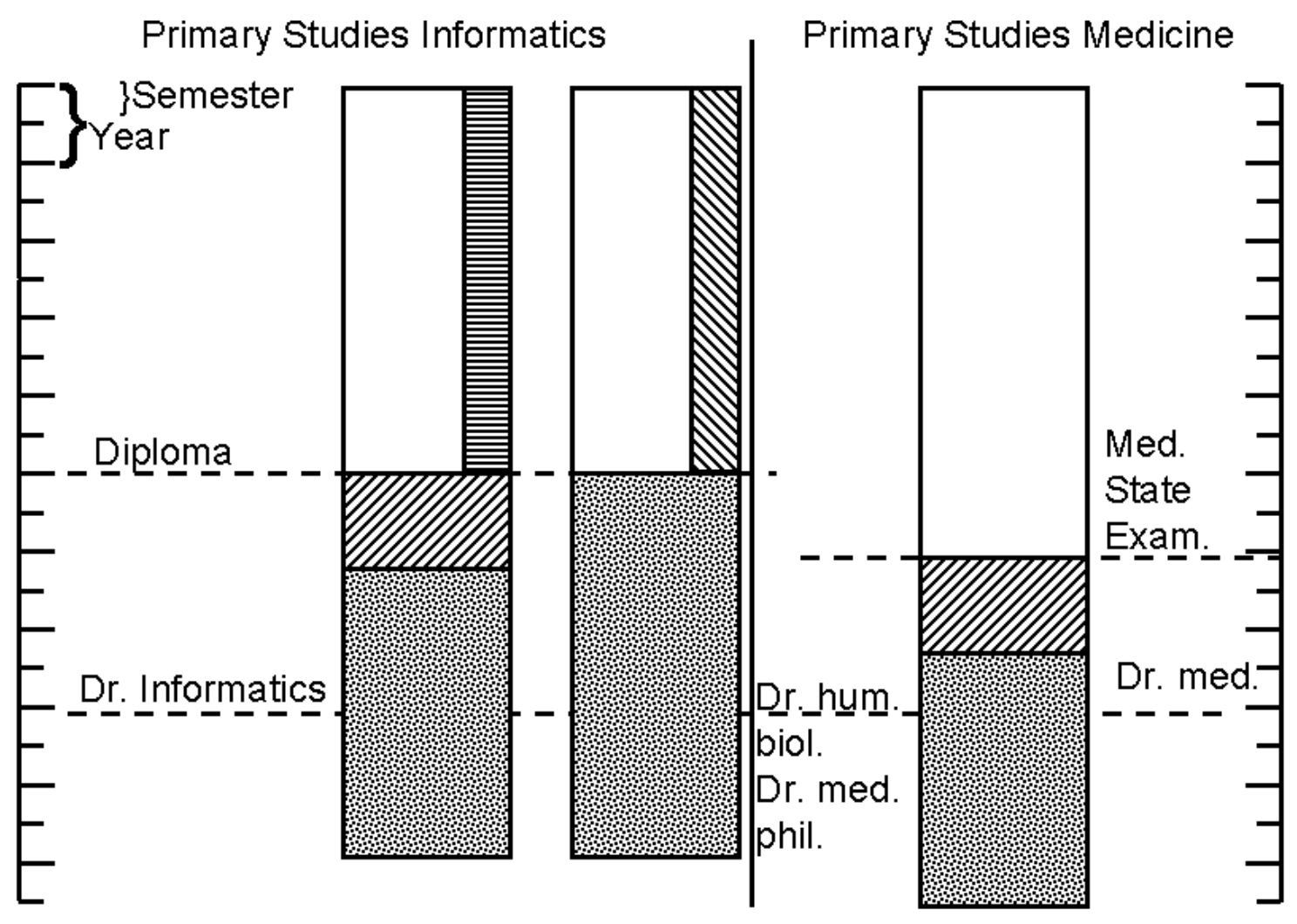

Application Subject Medicine

Addit. Studies Med. or Inf.

Other Application Subject

Operational Qualification 


\begin{tabular}{|c|c|c|}
\hline Core & $\begin{array}{l}\text { Minimal Duration } \\
\text { (months) }\end{array}$ & Subject \\
\hline $\mathrm{C}$ & 3 & Documentation in Medicine \\
\hline & 3 & Management of a Computing Centre \\
\hline $\mathrm{C}$ & 10 & Medical Information Systems \\
\hline $\mathrm{C}$ & 6 & $\begin{array}{c}\text { Process Control and Realtime Problems: } \\
\text { - } \quad \text { Biosignal processing } \\
\text { - Laboratory information systems } \\
\text { - Intensive care/patient monitoring } \\
\text { - }\end{array}$ \\
\hline $\mathrm{C}$ & 2 & Biometric counseling \\
\hline C & 3 & Organization \\
\hline & & $\begin{array}{l}\text { - Hospital administration } \\
\text { - } \quad \text { Public health service }\end{array}$ \\
\hline $\mathrm{C}$ & 0 & $\begin{array}{c}\bullet \quad \text { Screening centres } \\
\text { Research institutions }\end{array}$ \\
\hline
\end{tabular}

Selections are possible among the bulleted subjects.

Times spent in pertinent areas outside medical informatics can be admitted for recognition as operational qualification. The decision regarding the recognition of quantitative components should be left to the institution granting the certificate, or a commission charged with this responsibility.

The granting of the certificate should also require the proof of independent scientific activity in medical informatics. This could be done in the form of completed projects or scientific publications.

The activities have to be attested by the officers responsible for the institutions where they were conducted. Granting of the entitlement of institutions to provide education is also the responsibility of the institution that issues the certificate. The authority charged with this responsibility has yet to be defined. Candidates include the Society for Informatics, the German Society for Medical Documentation and Statistics (GMDS), the Section Medical Informatics of the GMDS, as well as a special commission composed of members of the identified societies. These issues have to be discussed in the responsible constituents of the identi- fied scientific societies. The discussion should be expedited, however.

\section{Agenda item 5: Strategy to Achieve Realization}

The medical participants suggest pursuing the definition of a medical specialty [in medical informatics] with high priority, in order to create pressure that results in equalization of informaticians through the certificate. The participating informaticians caution that such an equalization may in practice proceed very hesitatingly, if at all.
Attendance list Reisensburg

\section{Agenda item 6: Final Paper}

The revised minutes are to be considered as common final paper. It is to be prepared and passed to the participants in the workshop for review and validation. It is then to serve as a basis for discussions in the participating societies.

The minutes were prepared during the Reisensburg Workshop by the following gentlemen:

May 2, 1973, morning: Dr. Schuster, Wiesbaden

May 2, 1973, afternoon: Dr. W.

Gaus, Ulm

May 2, 1973, evening: Dr. Fischer, Munich

May 3, 1973, morning, Dr.

Selbmann, Ulm

May 3, 1973, afternoon,Dr. Gnatz, Munich

May 3, 1973, evening, Dr. Gnatz,

Munich

May 4, 1973, morning, Dr. Moehr,

Hanover

P.L. Reichertz

\begin{tabular}{|l|c|c|c|c|c|}
\hline & \multicolumn{2}{|c|}{ |lednesday, May 2 } & \multicolumn{2}{|c|}{ Thursday, May 3 } & Friday, May 4 \\
\hline & $\mathrm{M}$ & $\mathrm{A}$ & $\mathrm{M}$ & $\mathrm{A}$ & M \\
\hline Brauer & $\mathrm{X}$ & $\mathrm{X}$ & $\mathrm{X}$ & $\mathrm{X}$ & $\mathrm{X}$ \\
Deussen & & $\mathrm{X}$ & $\mathrm{X}$ & $\mathrm{X}$ & $\mathrm{X}$ \\
Dierstein & & & & $\mathrm{X}$ & $\mathrm{X}$ \\
Gnatz & $\mathrm{X}$ & $\mathrm{X}$ & $\mathrm{X}$ & $\mathrm{X}$ & $\mathrm{X}$ \\
Goos & & $\mathrm{X}$ & $\mathrm{X}$ & & \\
Herschel & $?$ & $\mathrm{X}$ & $\mathrm{X}$ & & \\
Unger & $\mathrm{X}$ & $\mathrm{X}$ & $\mathrm{X}$ & & \\
Dudeck & & & & $\mathrm{X}$ & $\mathrm{X}$ \\
Fischer & $\mathrm{X}$ & $\mathrm{X}$ & $\mathrm{X}$ & $\mathrm{X}$ & $\mathrm{X}$ \\
Gaus & $\mathrm{X}$ & $\mathrm{X}$ & $\mathrm{X}$ & $\mathrm{X}$ & $\mathrm{X}$ \\
Hietzker & $\mathrm{X}$ & & & & \\
Klesper & $\mathrm{X}$ & $\mathrm{X}$ & $\mathrm{X}$ & $\mathrm{X}$ & $\mathrm{X}$ \\
Moehr & $\mathrm{X}$ & $\mathrm{X}$ & $\mathrm{X}$ & $\mathrm{X}$ & $\mathrm{X}$ \\
Reichertz & $\mathrm{X}$ & $\mathrm{X}$ & $\mathrm{X}$ & $\mathrm{X}$ & $\mathrm{X}$ \\
Schuster & $\mathrm{X}$ & $\mathrm{X}$ & $\mathrm{X}$ & $\mathrm{X}$ & $\mathrm{X}$ \\
Selbmann & $\mathrm{X}$ & $\mathrm{X}$ & $\mathrm{X}$ & $\mathrm{X}$ & \\
Uberla & $\mathrm{X}$ & & & $\mathrm{X}$ & \\
Wagner & & &
\end{tabular}

